(C) This manuscript version is made available under the CC-BY-NC-ND 4.0 license https://creativecommons.org/licenses/by-nc-nd/4.0/

https://pubs.acs.org/doi/abs/10.1021/acssuschemeng.5b01612

\title{
Development of a Green Technology for Mercury Recycling from Spent Compact Fluorescent Lamps Using Iron Oxides Nanoparticles and Electrochemistry
}

\author{
Zhenzhong Hu, Uday Kurien, Kuzivakwashe Murwira, Avik Ghoshdastidar, Oleg Nepotchatykh, \\ and Parisa A. Ariya
}

\begin{abstract}
:
The widespread use of energy efficient mercury containing lamps and impending regulations on the control of mercury emissions has necessitated the development of green mercury control technologies such as nanosorbent capture and electrolysis regeneration. Herein we describe a two-step green technique to remove and recycle mercury from spent compact fluorescent lamps (CFLs). The first element included the assessment of capture efficiencies of mercury vapor on magnetite $\left(\mathrm{Fe}_{3} \mathrm{O}_{4}\right)$ and maghemite $\left(\gamma-\mathrm{Fe}_{2} \mathrm{O}_{3}\right)$, naturally abundant and ubiquitous components of atmospheric dust particles. Around $60 \mu \mathrm{g}$ of mercury vapor can be removed up to $90 \%$ by $1.0 \mathrm{~g}$ of magnetite nanoparticles, within a time scale of minutes. The second step included the development of an electrochemical system for the mercury recycling and regeneration of used nanoparticles. Under optimized conditions, up to $85 \%$ of mercury was recovered as elemental mercury. Postelectrolysis regenerated iron oxide nanoparticles were used in several sorption-electrolysis cycles without loss of the adsorption capacity, morphology, and surface area. The low energy usage for electrolysis can be supplied by the solar panels. The implications of our results within the context of green technology are herein discussed.
\end{abstract}

\section{Introduction}

Mercuryhasbeenknown to humanity for several millenniaand has key uses in fields including medicine, catalysis, optics, and energy-efficient technology. ${ }^{1}$ Yet it remains one of the most toxic global pollutants in the environment. ${ }^{1-3}$ Mercury compounds are known for being persistent, toxic, and bioaccumulative pollutants of global interest. Because of the toxicity of mercury compounds, which is quite compound selective, mercury usage has been of concern during the last few decades. Human casualties as a result of mercury poisoning due to the release of methyl mercury in the industrial wastewater from the 1930s to 1960s in Minamata Japan, and in 1971 in the Iraqi disaster, where organomercury fungicide treated seed grains were consumed by humans, are some highlights of the adverse effects of mercury toxicity in our ecosystem. ${ }^{1}$ The urgency in preventing future mercury related disasters and reducing the impact of chronic trace level exposure, prompted the signing of the 2013 UNEP Minamata Convention by 128 countries around the world, to control and "where feasible reduce atmospheric emissions from point sources. ${ }^{4}$ Among the recommendation of the Minamata convection (2013) is indeed the reduction of mercury emission from $\mathrm{Hg}$ containing lamps, which is the subject of the present study.

Volatile mercury species, predominantly elemental gaseous mercury $\left(\mathrm{Hg}_{(\mathrm{g})}^{0}\right)$ exist in the atmosphere through predominantly anthropogenic activities, and undergo (photo) chemical transformation. Upon deposition, predominantly oxidized mercury species can deposit on the Earth's surface and potentially be bioaccumulative in the aquatic food chains. One of the increasingly important sources of mercury usage in industry is associated with energy efficient mercury-containing lamps (MCLs) including fluorescent lamps, high intensity discharge (HID) lamps, and compact fluorescent lamps (CFLs). CFLs use $20-25 \%$ of the energy required for incandescent and other lighting technologies, ${ }^{5}$ and with potential regulation of incandescent lighting bulbs by governments, CFLs have seenincreasing usage in building, street, and industrial lighting. ${ }^{6}$

The release of mercury into the environment from MCLs has been identified by the Minimata convention as an ongoing concern, ${ }^{4}$ yet their disposal is poorly regulated globally. Eckelman et al. evaluated that only $20 \%$ of these lamps are recycled in the Organization for Economic Co-operation and Development (OECD) countries, 5\% in 
(C) This manuscript version is made available under the CC-BY-NC-ND 4.0 license https://creativecommons.org/licenses/by-nc-nd/4.0/

https://pubs.acs.org/doi/abs/10.1021/acssuschemeng.5b01612

developing countries and $0 \%$ in the least-developed countries. ${ }^{1}$ Without proper disposal, these MCLs can lead to significant mercuryemissions into the atmosphere from breakage and landfill evaporation. ${ }^{7}$

Existing CFLs recycling processes are aimed at reducing human exposure and recycling all of the components of the lamps, from the glass to the mercury, safely. ${ }^{8}$ Conventional industrial mercury recycling operations involve the processing and physical separation of fluorescent lamps into streams of fluorescent lamp end-caps, clean soda-lime glass, phosphor powder, and, eventually elemental mercury. ${ }^{8}$ Thermal-desorption of mercury from lamps followed by distillation techniques to recover mercury is currently a widely used method for recycling mercury from spent CFLs. Though this method is highly effective in recovering mercury ( $>99.95 \%$ recovery possible), the process itself is energy intensive. ${ }^{9,10}$ There is a need for a more energy-efficient yet effective process. Another recycling technique involves an advanced oxidation heterogeneous photocatalytic process that thus far has been studied at bench scale and is able to recover more than $99 \%$ of spent mercury. The disadvantage of the heterogeneous photocatalytic technique is its inconvenience, time-consumption, and relative expense. ${ }^{11}$ Furthermore, the introduction of oxidizers and reductants may introduce secondary contaminants into the environment.

Adsorption is another promising method for the mercury remediation and recycling from waste CFLs. The most common adsorbents for mercury include activated carbon, alumina and silica gels, and nanoparticles, such as iron oxides, due to their high surface-to-volume ratios. Magnetic iron oxides are particularly favorable as these particles can be sequestered using magnetism. They are used in adsorption columns, ion exchange, filter membranes and electrolysis for remediation purposes. ${ }^{12-18}$

To develop a green technology using natural-occurring chemicals, which removes and recycles mercury containing lamps, with minimal usage of energy, we opted for a novel experimental setup, which involved two elements. First, the mercury removal step involves adsorption of gaseous elemental mercury on iron oxides nanoparticles, which are ubiquitous in atmospheric dust particles. Second, the recycling step that includes electrochemical recovery of elemental mercury, which we have previously demonstrated to be energy neutral. Herein, we discuss the development of the new technology, and its advantages, shortcomings, and future development in light of the green economy.

\section{Experimental section}

Materials and Supplies. $\mathrm{FeCl}_{2} \cdot 4 \mathrm{H}_{2} \mathrm{O}$ and $\mathrm{FeCl}_{3} \cdot 6 \mathrm{H}_{2} \mathrm{O}, \mathrm{NaCl}$, and hydrous $\mathrm{NaOH}$ pellets were used as purchased. Commercial magnetite and maghemite nanoparticles were purchased from Sigma-Aldrich without further purification. Platinum gauze and iron mesh wire were used. Electrolyte solutions were prepared using ultrapure water from a Millipore Milli-Q $(18.2 \mathrm{M} \mathrm{Ohm} \cdot \mathrm{cm})$. Two different brands of CFLs were chosen to use in this study respectively.

Synthesis and Characterization of Iron Oxides Nano- particles. Magnetite $\left(\mathrm{Fe}_{2} \mathrm{O}_{3} \cdot \mathrm{FeO}\right) \mathrm{NPs}$ were prepared according to the method reported by Massart. ${ }^{19}$ Briefly, $\mathrm{FeCl}_{3} \cdot 6 \mathrm{H}_{2} \mathrm{O}$ and $\mathrm{FeCl}_{2} \cdot 4 \mathrm{H}_{2} \mathrm{O}$ solutions were mixed with a 2:1 molar ratio followed by the addition of ammonium hydroxide in $85{ }^{\circ} \mathrm{C}\left(0{ }^{\circ} \mathrm{C}=273 \mathrm{~K}\right)$ deoxygenated water. The precipitate was washed with deoxygenated water for three times. The resulting nanoparticles were collected with a magnetic retriever and dried overnight in an air ventilated oven. The maghemite $\left(\gamma-\mathrm{Fe}_{2} \mathrm{O}_{3}\right)$ nanoparticles were used as purchased from Sigma-Aldrich.

$\mathrm{Fe}_{3} \mathrm{O}_{4}$ and $\gamma-\mathrm{Fe}_{2} \mathrm{O}_{3}$ nanoparticles were characterized by complementary analytical methods. High-resolution transmission electron microscopy(HR-TEM) images were obtained using a Philips CM200 kV TEM with energy-dispersive X-ray spectroscopy (EDS). X-ray diffraction (XRD) patterns were taken on a Siemens D5000 diffractometer with Cu K $\alpha$ radiation source $(\lambda=1.5418$ $\AA$ ). Brunauer-Emmett-Teller (BET) specific surface area (SSA) was analyzed using the nitrogen adsorption method on a TriStar 3000 V6.07 surface area analyzer at $77 \mathrm{~K}$.

Iron Oxides Nanoparticles Loaded with Elemental Mercury Vapor. Three-necked round-bottomed flasks were coated with dimethyldichlorosilane (DMDCS) prior to use so as to prevent mercury vapor from adsorbing onto the inner glass surfaces of the vessels. Control mercury vapor adsorption experiments were carried out using the Schlenk technique. ${ }^{12,15}$ Stock mercury vapor was freshly made by vacuum transfer from a saturated mercury vapor vessel. Some of the mercury vapor was transferred to an identical $2 \mathrm{~L}$ flask with previously loaded iron oxides nanoparticles inside. The amount of mercury vapor transferred to the flask was calculated by difference in the mercury vapor stock solution between transfers. The absorption experiments were conducted in a room where the temperature was maintained at a constant $25 \pm 2{ }^{\circ} \mathrm{C}$.

For the adsorption experiments with cracked compact fluorescent lamps (CFLs), the schematic setup is shown in Figure S1 
(C) This manuscript version is made available under the CC-BY-NC-ND 4.0 license https://creativecommons.org/licenses/by-nc-nd/4.0/

https://pubs.acs.org/doi/abs/10.1021/acssuschemeng.5b01612

(Supporting Information). The $5000 \mathrm{~mL}$ vessel is first silylated prior to use. 4.0 g nanoparticles were added into the trap with silylated glass wool as copacking factor so as to maintain the void space. A lamp was placed inside the vessel and the vessel was sealed and connected as per the above setup. A metal rod, passing through a vessel neck septa, was used to break the lamp to release the mercury vapor contained within the bulb. The trap loaded with iron oxides nanoparticles and a gas- circulating pump were connected together with the flask. Blanks are taken of the air inside the vessel in triplicate before the lamp is broken. Samples are taken over consecutive periods and analyzed so as to obtain the transient mercury concentration profile inside the vessel. With this information it is then possible to determine the saturation point, after which the pump and trap system is initiated to capture the mercury. Cold vapor atomic fluorescence spectroscopy (CV-AFS) and gas chromatography mass spectrometry (GC-MS) were used to monitor the mercury vapor concentrations. CV-AFS was equipped with a Tekran Model 2600 CVAFS Mercury analysis system. A soda lime cartridge was used to filter the samples before analysis. GC-MS analyses were using an Agilent Technologies G5140A GC system coupled to an Agilent Technologies 5973 mass selective detector (MSD). The GC system was equipped with electronic pressure control, split/splitless and a capillary column HP-5 (column length:

$30.0 \mathrm{~m}$ and column diameter: $0.25 \mathrm{~mm}$ ).

Following the mercury capture process, the mercury-loaded iron oxides nanoparticles were transferred to the electrochemical regeneration chamber. Before transferring the nanoparticles to the electrolysis cell, we use liquid nitrogen to cool down the nanoparticles in order to avoid releasing mercury vapor into air during the transfer process.

Experimental Setup for Electrolysis. Electrolysis experiments were performed in a divided electrochemical glass cell. Iron mesh $(2.54 \mathrm{~cm} \times 5.08 \mathrm{~cm})$ and platinum wire mesh $(2.54 \mathrm{~cm} \times 2.54 \mathrm{~cm})$ were used for the cathode and anode, respectively. The simplified schematic of the electrochemical regeneration apparatus is shown in Figure S2 (Supporting Information), which consisted of two glass half cells and a power supply. One analytical grade gold trap was connected to the reduction cell to capture the $\mathrm{Hg}^{0}(\mathrm{~g})$ vapor that evaporated from the solution. After the electrolysis experiment, the iron mesh cathode was transferred to a silylated $4 \mathrm{~L}$ spherical Pyrex vessel with an iron bar. A mini induction heater was used to heat the iron mesh releasing the mercury.

Elemental Mercury Analysis. The removal efficiency and electrochemical regeneration efficiency were calculated based on the concentrations of mercury vapor by complementary CVAFS and GC- MS. We used the value of saturated mercury vapor pressure to make the calibration curve for the two detection methods. Aqueous mercury ion analysis was measured with PerkinElmer FIMS-400 Cold Vapor Mercury analysis system with Amalgam accessory

\section{RESULTS AND DISCUSSION}

We will present and discuss our results on both adsorption and recycling of nanoparticles, and present further physical and chemical characterization to ensure the high quality of green technology.

Characterization of the Iron Oxides NPs. As shown in Figure 1, the identities of iron oxides nanoparticles were confirmed by comparing X-ray diffraction patterns to standards in the Joint Committee on Powder Diffraction Standards (JCPDS) database. The relative XRD peak intensities of the synthetic $\mathrm{Fe}_{3} \mathrm{O}_{4}$ and commercial $\gamma$-Fe $\mathrm{O}_{3}$ nanoparticles matched those of reference $\mathrm{Fe}_{3} \mathrm{O}_{4}$ (JCPDS card 19-0629) and $\gamma-\mathrm{Fe}_{2} \mathrm{O}_{3}$ (JCPDS card 39-1346). The average crystallite size of $\mathrm{Fe}_{3} \mathrm{O}_{4}$ and $\gamma-\mathrm{Fe}_{2} \mathrm{O}_{3}$ NPs were calculated to be 6.3 and $19.8 \mathrm{~nm}$ respectively based on the Debye-Scherer eq (eq 1), ${ }^{20}$ where $\beta$ is the full width at half-maximum (fwhm) value of the XRD lines and $\theta$ is half of diffraction angle $2 \theta$.

$$
D=\frac{0.9 \lambda}{\beta \cos \theta}
$$

The TEM images (Figure 2) of the synthesized $\mathrm{Fe}_{3} \mathrm{O}_{4}$ NPs show a narrow size distribution ranging from 8-15 nm in diameter. The $\mathrm{\gamma}-\mathrm{Fe}_{2} \mathrm{O}_{3}$ NPs purchased from Sigma-Aldrich had a broader size distribution ranging from 25-125 $\mathrm{nm}$ in diameter. The BET surface area (SSA) of $\mathrm{Fe}_{3} \mathrm{O}_{4}$ and $\mathrm{\gamma}-\mathrm{Fe}_{2} \mathrm{O}_{3} \mathrm{NPs}$ was 106 and $40 \mathrm{~m}^{2} / \mathrm{g}$, respectively. 
(C) This manuscript version is made available under the CC-BY-NC-ND 4.0 license https://creativecommons.org/licenses/by-nc-nd/4.0/

https://pubs.acs.org/doi/abs/10.1021/acssuschemeng.5b01612

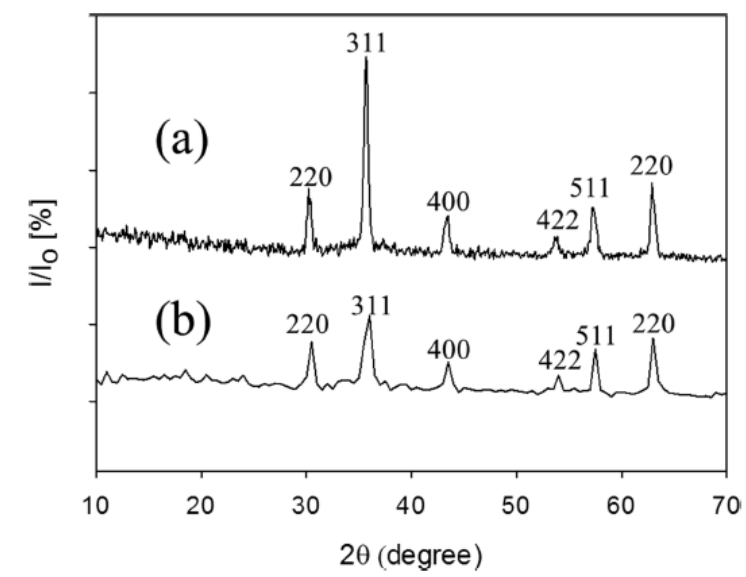

Figure 1. Typical X-ray diffraction patterns of (a) synthesized $\mathrm{Fe}_{3} \mathrm{O}_{4}$ NPs in this study and (b) commercial $\mathrm{Fe}_{3} \mathrm{O}_{4}$ NPs purchased from Sigma-Aldrich.

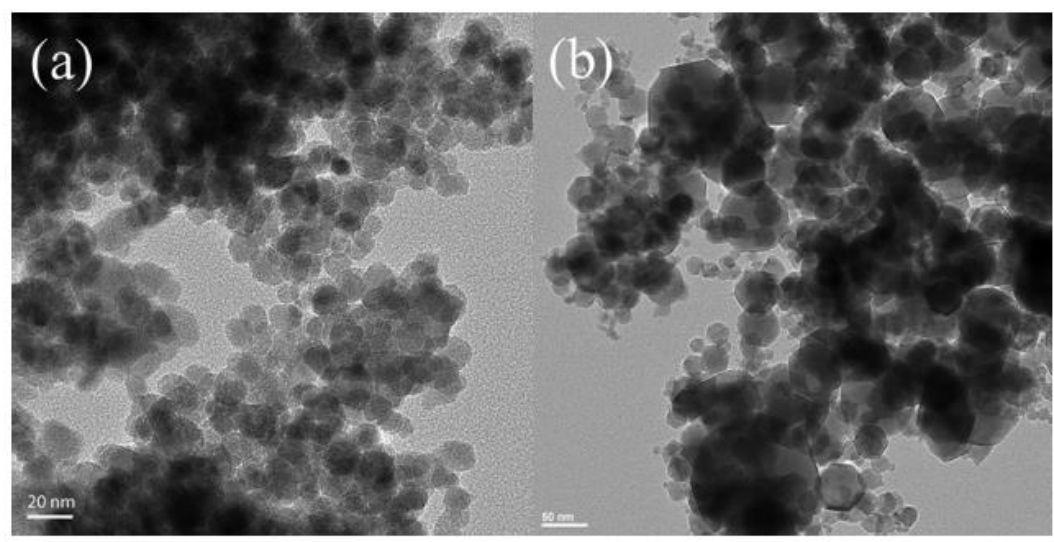

Figure 2. Typical TEM images of (a) synthesized $\mathrm{Fe}_{3} \mathrm{O}_{4} \mathrm{NPs}$ and (b) $\gamma-\mathrm{Fe}_{2} \mathrm{O}_{3}$ nanoparticles purchased from Sigma-Aldrich in this study.

Adsorption Capacities of Mercury Vapor by Iron Oxides. The iron oxides nanoparticles'adsorption capacities for mercury vapor were investigated at the first stage of this study. The adsorption capacities can be measured by calculating the removal efficiency $(\mathrm{RE})$ of mercury vapor as described in eq 2 , where $C_{\text {Initial }}$ and $C_{\text {Final }}$ are the mercury vapor concentrations in treated flask. For each experiment, we carried out at least three replicates and used a reference flask for comparison. The reference and treated flasks are two flasks of identical shape, with and without nanoparticles inside, respectively.

$$
R E(\%)=\frac{C_{\text {initial }}-C_{\text {final }}}{C_{\text {initial }}} \times 100
$$

For the commercial magnetite nanoparticles, the adsorption capacity of mercury vaporcanbe neglected. The main reason is that the PVB (poly(vinylpyrrolidone)) surfactant coated on the commercial magnetite nanoparticles may sterically block the adsorption site for mercury vapor. For the synthesized magnetite nanoparticles, we observed that $1.0 \mathrm{~g}$ of dispersed $\mathrm{Fe}_{3} \mathrm{O}_{4} \mathrm{NPs}$ can remove up to $16 \mu \mathrm{g}$ of mercury vapor with an efficiency of $98 \%$ in approximately $2.0 \mathrm{~h}$ (Figure 3). Consistent with BTEX compound adsorption by $\mathrm{Fe}_{3} \mathrm{O}_{4} \mathrm{NPs}$, the adsorption capacity for the mercury vapor was also dependent on the size and surface area of the synthesized nanoparticles. ${ }^{15}$

We observed that the smaller size and larger BET surface area of $\mathrm{Fe}_{3} \mathrm{O}_{4} \mathrm{NPs}$ demonstrated more elevated adsorption 
(C) This manuscript version is made available under the CC-BY-NC-ND 4.0 license https://creativecommons.org/licenses/by-nc-nd/4.0/

https://pubs.acs.org/doi/abs/10.1021/acssuschemeng.5b01612

capacity. It has also been reported magnetite can reduce $\mathrm{Hg}^{2+}$ to $\mathrm{Hg}^{0}$ in deoxygenated solutions, with the extent of the reduction dependent on the reduced state of the magnetite particles. ${ }^{21,22}$ Conversely, $\mathrm{Hg}^{0}$ adsorption by magnetite nanoparticles is dependent on a combination of the physical and chemical properties of the nanoparticles and adsorption conditions. Interestingly, aged $\mathrm{Fe}_{3} \mathrm{O}_{4} \mathrm{NPs}$ are observed to show better adsorption activity than the freshly prepared NPs, which suggests partially oxidized surfaces may elevated adsorption activity. This interesting finding also suggests the $\mathrm{Fe}_{3} \mathrm{O}_{4} \mathrm{NPs}$ can be recycled and reused for mercury capture. As reported before by other groups, $\mathrm{Hg}^{0}$ can act as a Lewis base and can be an electron-pair donor for physical adsorption. ${ }^{23-27}$ Cation vacancies on the magnetite surface can act as Lewis acid sites and provide the active sites for the physical adsorption of $\mathrm{Hg} .{ }^{28}$ For the commercial maghemite $\left(\mathrm{Y}-\mathrm{Fe}_{2} \mathrm{O}_{3}\right)$ nanoparticles, only $45 \%$ of $\mathrm{Hg}^{0}$ was removed in $3.0 \mathrm{~h}$ by $1.0 \mathrm{~g}$ of maghemite. As shown in Figure 4A, the removal efficiency did not increase significantly even with an extended adsorption time of 12.0 hnor did it increased remarkably with the addition of nano particles' amount to $2.0 \mathrm{~g}$. It is possibly that the adsorption kinetics mainly depends on the amounts of nanoparticles covering the surface of absorption vessel that contacts directly to the mercury vapor. Increasing the mass of nanoparticles alone does not effectively increase the surface area covered on the flask. However, if we perform adsorption experiments in a photochemical reaction chamber and introduce either warm white light or UV light during the adsorption, 90\% removal efficiency can be reached in 30 min (Figure 4B). As Worathanakul et al. described, the adsorption of mercury vapor by iron oxides nanoparticles may be UV irradiation active. ${ }^{29}$ Insignificant adsorption of mercury vapor in dark environment also confirmed this speculation.

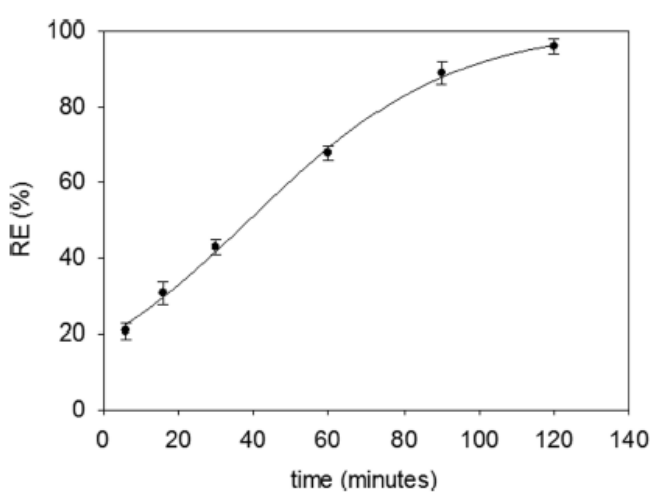

Figure 3. Average mercury vapor adsorption by various $\mathrm{Fe}_{3} \mathrm{O}_{4} \mathrm{NPs}$, as a function of time. The error bars indicate the uncertainties associated with minimum of 3 repetitions.

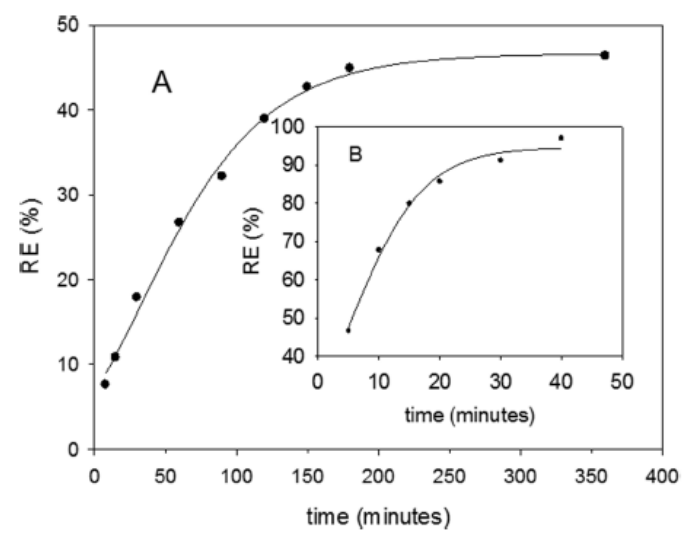

Figure 4. Mercury vapor adsorption by $\gamma-\mathrm{Fe}_{2} \mathrm{O}_{3} \mathrm{NPs}$, as a function of time. Panel A shows data taken under laboratory light conditions and panel B depicts data upon exposure white light.

As the results are shown in Figures 3 and 4, the magnetite and maghemite nanoparticles are effective for the adsorption of mercury vapor. Moreover, mercury capture from broken CFLs has also been investigated. As shown in Figure S1, spent compact fluorescent lamps were first broken in the $5 \mathrm{~L}$ vessel. After a $24 \mathrm{~h}$ desorption period, the amount of mercury vapor released from the two brands of lamps were 56 and $68 \mu \mathrm{g}$, respectively. The total mercury vapor released from the lamp greatly depends on the vendors of manufacture, lamp size and release time. After 3 days, the mercury vapor concentration reached saturation in the $5 \mathrm{~L}$ vessel. As Johnson et al. have reported before, over 1.34 $\mathrm{mg}$ of mercury could be released from a $13 \mathrm{~W}$ bulb. ${ }^{30}$ Mercury release from spent CFLs is known to be slow under ambient conditions and primarily caused by desorption/evaporation phenomena. Net mercury vapor concentration changes very little after $24 \mathrm{~h}$ though mercury vapor will continue to desorb/evaporate long until equilibrium is reached. After a $24 \mathrm{~h}$ desorption time, the pump and trap system was initiated to begin mercury capture. As shown in Figure 5, the released mercury vapor frombothlamps can be removed up to $90 \%$ in $1.0 \mathrm{~h}$. The induced flow of mercury through use of a pump and carrier gas systemincreases the contact surface area and contact time between nanoparticles and mercury therefore improving on recovery efficiencies. Adsorption time can also be significantly decreased to 30 and $15 \mathrm{~min}$ if the trap was cool down to 18.0 and $0{ }^{\circ} \mathrm{C}$, respectively. The mercury vapor adsorption capacities of iron oxides were measured to range between 140 to $170 \mu \mathrm{g} / \mathrm{g}$. Johnson et al. have highlighted a series of low-temperature mercury vapor sorbents. ${ }^{30}$ Adsorption capacities range over 7 orders of magnitude, from 0.005 (Zn micropowder) to $188000 \mu \mathrm{g} / \mathrm{g}$ (unstabilized nano-Se), depending on sorbent chemistry and particle size. Compared to other sorbents tested, iron oxides had relatively lower adsorption capacities, yet it is still high enough to be a viable efficient interface for industrial usage. Moreover, the application of naturally occurring iron oxides sorbents will not generate byproducts waste harmful to the environment, in contrast to other techniques. Great potential exists in the recycling of sorbents and recovery of mercury vapor, as shown in the next section. The strong magnetic 
(C) This manuscript version is made available under the CC-BY-NC-ND 4.0 license https://creativecommons.org/licenses/by-nc-nd/4.0/ https://pubs.acs.org/doi/abs/10.1021/acssuschemeng.5b01612

properties of the iron oxides will be convenient for the process the waste management.

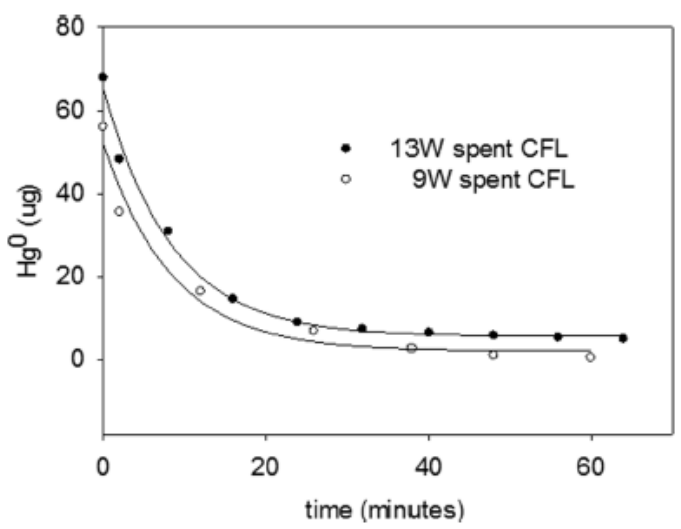

Figure 5. Removal efficiency of mercury vapor released from spent CFLs.

Electrochemical Recovery of Mercury. The electrochemical reduction efficiency of aqueous $\mathrm{Hg}^{2+}$ species was investigated using controls. $80 \mu \mathrm{L}$ of the $1.25 \mathrm{mg} / \mathrm{mL} \mathrm{Hg}\left(\mathrm{NO}_{3}\right)_{2} \cdot \mathrm{H}_{2} \mathrm{O}$ stock solution was added to the electrolyte. The reduction efficiency was determined by characterizing mercury deposition on the iron mesh cathode. More than $98 \%$ of the $\mathrm{Hg}^{2+}$ ions were reduced to elemental mercury through electrolysis. This can be attributed to the large surface area of the cathode, and the low quantity of $\mathrm{Hg}$ present in the system. It must be noted that efficient mixing of the electrolyte is necessary for the trace metal recovery. Mixing in the anode can maximize the diffusion rate of the oxidized mercury from the anode into the electrolyte thereby prevent supersaturation and crystallization of the salt within the vicinity of the anode. Similarly for the cathode, mixing can improve diffusion rates of $\mathrm{Hg}^{2+}$ onto the cathode surface for reduction.

Scheme 1. Proposed Reaction Path for the Electro-oxidation and Reduction of Elemental Mercury on the Anode and Cathode Respectively

Anode:

$$
\begin{aligned}
& 2 \mathrm{Cl}^{-} \rightleftharpoons \mathrm{Cl}_{2}+2 \mathrm{e} \\
& \text { Eq. (3) } \\
& \mathrm{Cl}_{2}+\mathrm{H}_{2} \mathrm{O} \rightleftharpoons \mathrm{H}^{+}+\mathrm{Cl}^{-}+\mathrm{HClO} \\
& \text { Eq. (4) } \\
& \mathrm{HClO} \rightleftharpoons \mathrm{H}^{+}+\mathrm{ClO}^{-} \\
& \text {Eq. (5) } \\
& \mathrm{Hg}^{0}+3 \mathrm{Cl}^{-}+\mathrm{H}^{+}+\mathrm{HClO} \rightleftharpoons \mathrm{HgCl}_{4}^{2-}+\mathrm{H}_{2} \mathrm{O} \\
& \text { Eq. (6) } \\
& \mathrm{Hg}^{0}+3 \mathrm{Cl}^{-}+\mathrm{ClO}^{-}+\mathrm{H}_{2} \mathrm{O} \rightleftharpoons \mathrm{HgCl}_{4}^{2-}+2 \mathrm{OH}^{-} \\
& \text {Eq. (7) }
\end{aligned}
$$

\begin{tabular}{|c|c|c|c|c|c|c|}
\hline $\begin{array}{c}\text { CFL } \\
\text { (sorbent) }\end{array}$ & total $\underset{(\mu \mathrm{g})}{\mathrm{Hg}^{0}}$ released & $\begin{array}{l}\mathrm{Hg} \text { left in adsorption } \\
\text { system }(\mu \mathrm{g})\end{array}$ & $\begin{array}{l}\mathrm{Hg} \text { on electrolysis } \\
\text { sorbent }(\mu \mathrm{g})\end{array}$ & $\begin{array}{l}\mathrm{Hg} \text { left in electrolyte } \\
(\mu \mathrm{g})\end{array}$ & $\begin{array}{l}\mathrm{Hg} \text { reduced on cathode } \\
(\mu \mathrm{g})\end{array}$ & $\begin{array}{c}\text { total } \mathrm{Hg}^{0} \\
\text { recoverable (\%) }\end{array}$ \\
\hline$\stackrel{13 \mathrm{~W}}{\left(\mathrm{Fe}_{3} \mathrm{O}_{4}\right)}$ & 42 & 1.8 & 1.3 & $2.7(0.05)^{a}$ & 36 & 98 \\
\hline $\begin{array}{l}9 \mathrm{~W}(\gamma- \\
\left.\mathrm{Fe}_{2} \mathrm{O}_{3}\right)\end{array}$ & 58 & 9.3 & 24.0 & $0.8(0.04)^{a}$ & 20 & 95 \\
\hline
\end{tabular}

Cathode:

$$
\begin{aligned}
& 2 \mathrm{H}_{2} \mathrm{O}+2 \mathrm{e} \rightleftharpoons \mathrm{H}_{2}+2 \mathrm{OH}^{-} \quad \text { Eq. (8) } \\
& \mathrm{HgCl}_{4}^{2-}+2 \mathrm{e} \rightleftharpoons \mathrm{Hg}^{0}+4 \mathrm{Cl}^{-} \quad \text { Eq. (9) }
\end{aligned}
$$

Table 1. Distribution of Mercury Vapor from Spent CFLs during Electrolysis Regeneration 
(C) This manuscript version is made available under the CC-BY-NC-ND 4.0 license https://creativecommons.org/licenses/by-nc-nd/4.0/ https://pubs.acs.org/doi/abs/10.1021/acssuschemeng.5b01612

The electrochemical regeneration of gaseous elemental mercury captured on nanoparticles was carried out in a divided cell (Figure S2, Supporting Information). Different electrolyte solutions, oxidation potential applied, and electrolysis time were all optimized. Sodium chloride and sodium hydroxide were used as electrolyte for the comparison. Although electrical current conducted through the solutions increased with sodium chloride concentration, the mercury reduction efficiency did not change significantly with the current if the charge passing through the system was maintained (Figure S3, Supporting Information). Therefore, in consideration of the electrolysis time, we chose $1.0 \mathrm{M}$ for the operation concentration. Sobral et al. have reported that high mercury extraction efficiency from mercury-loaded activated carbon could be achieved when using same concentration of electrolyte. ${ }^{31}$ The electrolytes were kept at the same concentration of $1.0 \mathrm{M}$. The electrolysis ran for $4.0 \mathrm{~h}$ in total with a current of $0.5 \mathrm{~A}$ so the elemental mercury can get complete oxidized and then reduced. For sodium chloride as an electrolyte, mercury recovery up to $85 \%$ can be obtained whereas only $50 \%$ recovery is reached using sodium hydroxide. The lower recovery could be explained through formation of insoluble $\mathrm{Hg}(\mathrm{OH})_{2}$ or $\mathrm{HgO}$, which inhibit the reduction of oxidized mercury to elemental mercury. Bolger and Szlag have reported that $\mathrm{KNO}_{3}$ was an efficient electrolyte for the direct electro-oxidation of mercury. ${ }^{32}$ However, strong acidic conditions are required and should be ruled out for iron oxide sorbents. Therefore, we choose sodium chloride as the desired electrolyte in this study. Meanwhile, $\mathrm{NaCl}$ has the advantage of naturally abundant and inexpensive.

The electroleaching process begins in the anode viacomplex reactions, which follow the generation of chlorine, and ultimately result in the oxidation of the adsorbed mercury into a more soluble form. We described the phenomena that elemental mercury got oxidized at anode and mercury ions were reduced at cathode in Scheme 1. As shown in eq 3, the chloride ions got oxidized at the anode surface and form chlorine once the current was applied. At the same time, water was reduced at the cathode to produce hydrogen and hydroxyl ions (eq 8; in the text). Meanwhile, hypochlorous acid and hypochlorite were generated at the anode by the chemical reaction and dissociation (eqs 4 and 5; in the manuscript). Once selected oxidative chlorine species were formed, the elemental mercury got oxidized to soluble $\mathrm{HgCl}^{2-}$ ions as shown in eqs 6 and 7. We cannot exclude the formation of other chlorine species such as chlorate and perchlorate and subsequently mercury chlorate and mercury perchlorate during the electrochemical

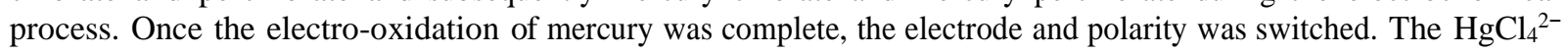
ions were reduced and elemental mercury was electrodeposited at the cathode surface (eq 9).

It should be noted that the $\mathrm{pH}$ value of the solution during

electrolysis also affects the mercury recovery efficiency. After the electrolysis, the $\mathrm{pH}$ value is expected to decrease in the anode and increase in the cathode, respectively. Strong acidic condition will likely weaken the robustness and integrity of iron oxides sorbents. ${ }^{33}$ The strong alkaline condition will facilitate the formation of insoluble mercury oxide and inhibit the reduction. ${ }^{34}$ For our system, we perform the whole electrolysis process in a weak acidic range of $\mathrm{pH}$ (between 5 and 7). Acidic condition has also been recommended to perform the mercury electro-leaching process by other research groups. ${ }^{31,32}$ It is likely the oxidation power increases at the acidic $\mathrm{pH}$ range because the generation of $\mathrm{HClO}$ is favored and therefore enhance the mercury dissolution and reduction. ${ }^{31}$

Under the optimized electrolysis conditions, we investigated the electrochemical system for recovering elemental mercury captured from broken CFLs. As shown in Table 1, the amounts of released mercury absorbed by the nano sorbents were 42 and $58 \mu \mathrm{g}$, respectively. After the electrochemical regeneration, 36 and $20 \mu \mathrm{g}$ of mercury were recovered from the cathode, accounting for $85 \%$ and $35 \%$ recoveries, respectively. Mercury losses were assessed for each stage of the process. First, residual mercury bound to the surface of NPs remaining in the adsorption vessel was quantified by adding smalls amount of aqua regia to digest the mercury within the vessel as well as to determine the mercury bound to the nanoparticles from the electrolysis process. As shown in Table 2, approximately 8\% of total mercury was left in the adsorption flask and magnetite sorbent and more than 55\% of total mercury has been detected in the adsorption flask when experiments with maghemite sorbent. The capture of mercury vapor, using maghemite nanoparticles, likely follows a photo-oxidation pathway producing $\mathrm{HgO}$, which can easily stick at the surface of the adsorption flask. Without strong acidic conditions, $\mathrm{HgO}$ was difficult to desorb from the maghemite sorbents and subsequently dissolve in solution for the following electro- chemical reduction. For magnetite, mercury vapor was likely captured by physical adsorption and the conductive magnetite nanoparticles favored electrochemical regeneration. Mercury left in the electrolyte may have been comprised of some mercury precipitate and unreduced mercury ions. Further research on detailed chemical speciation and quantification of different compounds, within the electrochemical chambers is recommended. In addition, such studies will provide a means for further optimization of recycling system. It should be noted that activated carbon can efficiently remove mercury in the electrolyte and can be regenerated by electrochemistry, ${ }^{32}$ as was the process used to quantify the $\mathrm{Hg}$ left in the electrolyte as shown in Table 1. 
(C) This manuscript version is made available under the CC-BY-NC-ND 4.0 license https://creativecommons.org/licenses/by-nc-nd/4.0/

https://pubs.acs.org/doi/abs/10.1021/acssuschemeng.5b01612

Table 2. Mercury Equilibrium Adsorption Capacities and Regeneration Efficiencies for Fresh and Recycled Magnetite Nanoparticles

\begin{tabular}{|c|c|c|c|}
\hline adsorbent & surface area $\left(\mathrm{m}^{2} \cdot \mathrm{g}^{-1}\right)$ & adsorption capacity $\left(\mu \mathrm{g} \cdot \mathrm{g}^{-1}\right)$ & RGE (\%) \\
\hline fresh & $106 \pm 6$ & $160 \pm 4$ & reference \\
\hline after first cycle & $98 \pm 6$ & $152 \pm 5$ & $102 \pm 4$ \\
\hline after second cycle & $104 \pm 6$ & $162 \pm 3$ & $108 \pm 4$ \\
\hline after third cycle & $102 \pm 6$ & $148 \pm 4$ & $96 \pm 2$ \\
\hline
\end{tabular}

Regeneration Cycle. Bolger and Szlag have reported that two different types of carbon cloth can be electrochemically regenerated after mercury adsorption experiments. ${ }^{32}$ After three regeneration cycles, the mercury equilibrium adsorption capacities and nitrogen BET surface areas of the two carbon cloths kept in a constant range. Recently, our group has reported that nano magnetite can be effectively regenerated by electrochemistry after VOC adsorption experiments. ${ }^{15}$ Note that VOC oxidations and interaction as cloud condensation nuclei have been identified in modeling studies. ${ }^{35}$ To assess how the electrochemical process preserves sorbent adsorption properties and remains intact, we use regeneration efficiency (RGE) to compare the adsorption efficiencies (AC) of mercury of fresh and regenerated nanoparticles. The RGE can be defined as the ratio of adsorption capacity of regenerated nano magnetite divided by the adsorption capacity of fresh nano magnetite as shown in eq 10.

$$
\text { regeneration efficiency }(\%)=\frac{A C_{\text {regenerated }}}{A C_{\text {fresh }}} \times 100
$$

With each adsorption/regeneration cycle, transfer losses of the iron oxides nanoparticles accounting for $5 \%$ by mass. Therefore, it is of great advantage to develop supported iron oxides nanoparticles to avoid the loss and dispersion of nanoparticles to the setup environment. We adjusted for the loss in mass of the nanoparticles for in the calculation of their regeneration efficiencies. As shown in Table 2, the regeneration efficiencies of the iron oxides nanoparticles ranged from $94 \%$ to $112 \%$ over three regeneration cycles with surface area and adsorption capacity of the magnetite nanoparticles relatively constant. It offers potential to upscale the experiments for future industrial use.

Concluding Remarks. We have developed an efficient system for the recovery of mercury vapor from spent CFLs using nanosorbents capture and electrolysis recovery. Magnet- ite nanoparticle sorbents can remove the mercury vapor by up to $90 \%$ within $1 \mathrm{~h}$ and can be regenerated without loss of activity. Mercury vapor can be recovered up to $85 \%$ in $4.0 \mathrm{~h}$ though absorption times can be greatly reduced through cooling of the sorbent trap to promote adsorption and heating of the spent CFL containing vessel to promote desorption. As for the cheapest magnetic nanoparticles, maghemite can uptake mercury vapor quickly with warm white light irradiation although it is not an ideal sorbent for electrochemical recovery. The mercury adsorption setup is easy to assemble and can be scaled up for potential use in industry by increasing the size of the trap and increasing the mass of sorbent to increase the total adsorption capacity. Results from our study and other group showed supported magnetite nanoparticles are efficient methods for the removal of pollutants. ${ }^{36,37}$ Supported magnet- ite nano particles are advantageous for increasing the surface area available for adsorption, maintaining the void space, without dispersal in the gas stream and avoiding undesirable side products or aerosols production. Finally, for the electro- chemical regeneration in this study, only $20 \mathrm{~W}$ of power was needed, which can be operated with solar panels such as our lab's 80 W SolarPanel Kit with Stand and inverter. Therefore, it has great potential to operate the electrolysis by solar energy. There are numerous solar panel units available in the market, both for laboratory scale and industrial systems. Further study is needed to operate the electrochemistry by solar energy and optimize for particular industrial operations.

\section{ASSOCIATED CONTENT Supporting Information}

The Supporting Information is available free of charge on the ACS Publications website at DOI: 10.1021/acssusche- meng.5b01612. 
(C) This manuscript version is made available under the CC-BY-NC-ND 4.0 license

https://creativecommons.org/licenses/by-nc-nd/4.0/

https://pubs.acs.org/doi/abs/10.1021/acssuschemeng.5b01612

Further details on the experimental device and more characterization and experimental results (PDF).

\section{AUTHOR INFORMATION}

Corresponding Author

${ }^{*}$ P. A. Ariya. Email: parisa.ariya@mcgill.ca.

Notes

The authors declare no competing financial interest.

\section{ACKNOWLEDGMENTS}

We gratefully acknowledge support of NanoQuebec/Prima

Quebec, FRQNT, and NSERC CREATE Mine of knowledge (project and PDF fellowship to Z.H.). We sincerely thank M. Ong and U. Shahed for making valuable comments to improve this paper.

\section{REFERENCES}

(1) Ariya, P. A.; Amyot, M.; Dastoor, A.; Deeds, D.; Feinberg, A.; Kos, G.; Poulain, A.; Ryjkov, A.; Semeniuk, K.; Subir, M.; Toyota, K. Mercury physicochemical and biogeochemical transformation in the atmosphere and at atmospheric interfaces: a review and future directions. Chem. Rev. 2015, 115, 3760-3802.

(2) Boening, D. W. Ecological effects, transport, and fate of mercury: a general review. Chemosphere 2000, 40, $1335-1351$.

(3) Ariya, P. A.; Peterson, K.; Snider, G.; Amyot, M. Mercury chemical transformations in the gas, aqueous and heterogeneous phases: state-of-the-art science and uncertainties. In Mercury fate and transport in the global atmosphere; Springer: New York, 2009; pp 459- 501.

(4) UN. Minamata Convention on Mercury; United Nations: New York, 2013.

(5) Khan, N.; Abas, N. Comparative study of energy saving light sources. Renewable Sustainable Energy Rev. 2011, 15, 296-309.

(6) Waide, P. Phase Out of Incandescent Lamps; OECD Publishing: Paris, 2010.

(7) Eckelman, M. J.; Anastas, P. T.; Zimmerman, J. B. Spatial assessment of net mercury emissions from the use of fluorescent bulbs. Environ. Sci. Technol. 2008, 42, 8564-8570.

(8) Rodríguez, O.; Padilla, I.; Tayibi, H.; Lópz-Delgado, A. Concerns on liquid mercury and mercury-containing wastes: A review of the treatment technologies for the safe storage. J. Environ. Manage. 2012, 101, 197-205.

(9) Chang, T.; You, S.; Yu, B.; Chen, C.; Chiu, Y. Treating high- mercury-containing lamps using full-scale thermal desorption technol- ogy. J. Hazard. Mater. 2009, 162, 967-972.

(10) Chang, T.-C.; You, S.-J.; Chen, C.; Lee, Y. Mercury removal from cold cathode fluorescent lamps using thermal desorption technology. Waste Manage. Res. 2010, 28, 455.

(11) Bussi, J.; Cabrera, M. N.; Chiazzaro, J.; Canel, C.; Veiga, S.; Florencio, C.; Dalchiele, E. A.; Belluzzi, M. The recovery and recycling of mercury from fluorescent lamps using photocatalytic techniques. J. Chem. Technol. Biotechnol. 2010, 85, 478-484.

(12) Eltouny, N. A.; Ariya, P. A. $\mathrm{Fe}_{3} \mathrm{O}_{4}$ nanoparticles and carboxymethyl cellulose: a green option for the removal of atmospheric benzene, toluene, ethylbenzene, and $o$-Xylene (BTEX). Ind. Eng. Chem. Res. 2012, 51, 12787-12795.

(13) Eltouny, N.; Ariya, P. A. Enhanced reactivity toward oxidation by water vapor: interactions of toluene and $\mathrm{NO}_{2}$ on hydrated magnetite nanoparticles. J. Phys. Chem. C 2014, 118, 23654-23663.

(14) Eltouny, N.; Ariya, P. A. Competing reactions of selected atmospheric gases on $\mathrm{Fe}_{3} \mathrm{O}_{4}$ nanoparticles surfaces. Phys. Chem. Chem. Phys. 2014, 16, 23056-23066.

(15) Hu, Z.; Beuret, M.; Khan, H.; Ariya, P. A. Development of a

recyclable remediation system for gaseous BTEX: combination of iron oxides nanoparticles adsorbents and electrochemistry. ACS Sustainable Chem. Eng. 2014, 2, 2739-2747.

(16) Ye, C.; Ariya, P. Co-adsorption of gaseous benzene, toluene,

ethylbenzene, $m$-xylene (BTEX) and $\mathrm{SO}_{2}$ on recyclable $\mathrm{Fe}_{3} \mathrm{O}_{4}$ nanoparticles at $0-101 \%$ relative humidities. J. Environ. Sci. 2015, 31, 164-174.

(17) Ambashta, R. D.; SillanpäM. Water purification using magnetic assistance: a review. J. Hazard. Mater. 2010, 180, $38-49$.

(18) Hua, M.; Zhang, S.; Pan, B.; Zhang, W.; Lv, L.; Zhang, Q. Heavy metal removal from water/wastewater by nanosized metal oxides: Areview. J. Hazard. Mater. 2012, 211-212, 317-331.

(19) Massart, R. Preparation of aqueous magnetic liquids in alkaline and acidic media. IEEE Trans. Magn. 1981, 17, 1247-1248.

(20) Holzwarth, U.; Gibson, N. The Scherrer equation versus the 'Debye-Scherrer equation'. Nat. Nanotechnol. 2011, 6, 534-534.

(21) Wiatrowski, H. A.; Das, S.; Kukkadapu, R.; Ilton, E. S.; Barkay, T.; Yee, N. Reduction of $\operatorname{Hg}(\mathrm{II})$ to $\mathrm{Hg}(0)$ by magnetite. Environ. Sci. Technol. 2009, 43, 5307-5313.

(22) Pasakarnis, T. S.; Boyanov, M. I.; Kemner, K. M.; Mishra, B.;O’Loughlin, E. J.; Parkin, G.; Scherer, M. M. Influence of chloride and $\mathrm{Fe}(\mathrm{II})$ content on the reduction of $\mathrm{Hg}(\mathrm{II})$ by magnetite. Environ. Sci. Technol. 2013, 47, 6987-6994.

(23) Yang, S.; Guo, Y.; Yan, N.; Qu, Z.; Xie, J.; Yang, C.; Jia, J. Capture of gaseous elemental mercury from flue gas using a magnetic and sulfur poisoning resistant sorbent $\mathrm{Mn} / \mathrm{Y}-\mathrm{Fe}_{2} \mathrm{O}_{3}$ at lower temperatures. J. Hazard. Mater. 2011, 186, 508-515.

(24) Yang, S.; Guo, Y.; Yan, N.; Wu, D.; He, H.; Qu, Z.; Jia, J. Elemental mercury capture from flue gas by magnetic Mn-Fe 
(C) This manuscript version is made available under the CC-BY-NC-ND 4.0 license

https://creativecommons.org/licenses/by-nc-nd/4.0/

https://pubs.acs.org/doi/abs/10.1021/acssuschemeng.5b01612

spinel: effect of chemical heterogeneity. Ind. Eng. Chem. Res. 2011, 50, 9650-9656.

(25) Yang, S.; Guo, Y.; Yan, N.; Wu, D.; He, H.; Xie, J.; Qu, Z.; Jia, J. Remarkable effect of the incorporation of titanium on the catalytic activity and $\mathrm{SO}_{2}$ poisoning resistance of magnetic $\mathrm{Mn}-\mathrm{Fe}$ spinel for elemental mercury capture. Appl. Catal., B 2011, 101, 698-708.

(26) Yang, S.; Yan, N.; Guo, Y.; Wu, D.; He, H.; Qu,Z.; Li, J.; Zhou, Q.; Jia, J. Gaseous elemental mercury capture from flue gas using magnetic nanosized $\left(\mathrm{Fe}_{3-\mathrm{x}} \mathrm{Mn}_{\mathrm{x}}\right)_{1-\delta} \mathrm{O}_{4}$. Environ. Sci. Technol. 2011, 45, 1540-1546.

(27) Xing, L.; Xu, Y.; Zhong, Q. Mn and Fe modified fly ash as a superior catalyst for elemental mercury capture under air conditions. Energy Fuels 2012, 26, 4903-4909.

(28) Laurent, S.; Forge, D.; Port, M.; Roch, A.; Robic, C.; Vander Elst, L.; Muller, R. N. Magnetic iron oxide nanoparticles: synthesis, stabilization, vectorization, physicochemical characterizations, and biological applications. Chem. Rev. 2008, 108, 2064-2110.

(29) Worathanakul, P.; Kongkachuichay, P.; Noel, J. D.; Suriyawong, A.; Giammar, D. E.; Biswas, P. Evaluation of nanostructured sorbents in differential bed reactors for elemental mercury capture. Environ. Eng. Sci. 2008, 25, 1061-1070.

(30) Johnson, N. C.; Manchester, S.; Sarin, L.; Gao, Y.; Kulaots, I.;Hurt, R. H. Mercury vapor release from broken compact fluorescent lamps and in situ capture by new nanomaterial sorbents. Environ. Sci. Technol. 2008, 42, 5772-5778.

(31) Sobral, L. G. S.; Santos, R. L. C.; Barbosa, L. A. D. Electrolytic treatment of mercury-loaded activated carbon from a gas cleaning system. Sci. Total Environ. 2000, 261, 195-201.

(32) Bolger, P. T.; Szlag, D. C. An electrochemical system for removing and recovering elemental mercury from a gas stream. Environ. Sci. Technol. 2002, 36, 4430-4435.

(33) Pang, S. C.; Chin, S. F.; Anderson, M. A. Redox equilibria of iron oxides in aqueous-based magnetite dispersions: Effect of $\mathrm{pH}$ and redox potential. J. Colloid Interface Sci. 2007, 311, 94-101.

(34) Hahne, H.; Kroontje, W. The simultaneous effect of $\mathrm{pH}$ and chloride concentrations upon mercury (II) as a pollutant. Soil Sci.Soc. Am. J. 1973, 37, 838-843.

(35) Von Salzen, K.; Leighton, H.; Ariya, P.; Barrie, L.; Gong, S.; Blanchet, J.-P.; Spacek, L.; Lohmann, U.; Kleinman, L. Sensitivity of sulphate aerosol size distributions and $\mathrm{CCN}$ concentrations over North America to $\mathrm{SO}_{\mathrm{x}}$ emissions and $\mathrm{H}_{2} \mathrm{O}_{2}$ concentrations. Journal of geophysical research 2000, 105, 9741-9765.

(36) Eltouny, N. A.; Ariya, P. A. $\mathrm{Fe}_{3} \mathrm{O}_{4}$ nanoparticles and carboxymethyl cellulose: a green option for the removal of atmospheric benzene, toluene, ethylbenzene, and $o$-xylene (BTEX). Ind. Eng. Chem. Res. 2012, 51, 12787-12795.

(37) Yuan, P.; Fan, M.; Yang, D.; He, H.; Liu, D.; Yuan, A.; Zhu, J.; Chen, T. Montmorillonite-supported magnetite nanoparticles for the removal of hexavalent chromium [Cr(VI)] from aqueous solutions. J. Hazard. Mater. 2009, 166, 821-829. 